\title{
Magnetic Field Energy Harvesting with a Lead-Free Piezoelectric High Energy Conversion Material
}

\author{
Quan Wang ${ }^{\dagger}$, Kyung-Bum Kim ${ }^{\dagger}$, Sang Bum Woo ${ }^{\dagger}$ and Tae Hyun Sung * \\ Department of Electrical Engineering, Hanyang University, Seoul 133-791, Korea; \\ wq799788180@hotmail.com (Q.W.); Inylove17@naver.com (K.-B.K.); wsb9393@naver.com (S.B.W.) \\ * Correspondence: sungth@hanyang.ac.kr \\ t These authors contributed equally to this work.
}

Citation: Wang, Q.; Kim, K.-B.; Woo, S.B.; Sung, T.H. Magnetic Field

Energy Harvesting with a Lead-Free Piezoelectric High Energy Conversion Material. Energies 2021, 14, 1346. https://doi.org/10.3390/ en14051346

Academic Editors: Sérgio Cruz and Krzysztof Górecki

Received: 18 January 2021

Accepted: 23 February 2021

Published: 2 March 2021

Publisher's Note: MDPI stays neutral with regard to jurisdictional claims in published maps and institutional affiliations.

Copyright: (c) 2021 by the authors. Licensee MDPI, Basel, Switzerland. This article is an open access article distributed under the terms and conditions of the Creative Commons Attribution (CC BY) license (https:/ / creativecommons.org/licenses/by/ $4.0 /)$.

\begin{abstract}
This article presents a high-performance lead-free piezoelectric energy harvester (LPEH) system for magnetic field. It based on a $\mathrm{Ba}_{0.85} \mathrm{Ca}_{0.15} \mathrm{Ti}_{0.90} \mathrm{Zr}_{0.10} \mathrm{O}_{3}+\mathrm{CuO} 0.3 \mathrm{wt} \%\left(\mathrm{BCTZC}_{0.3}\right)$ composite was fabricated by sintering at $1450{ }^{\circ} \mathrm{C}$. The $\mathrm{BCTZC}_{0.3}$ composite, which has an enhanced high energy conversion constant $\left(d_{33} \times g_{33}\right)$, shows improved piezoelectric power-generation performance when compared with conventional piezoelectric energy harvesters. The $\mathrm{BCTZC}_{0.3}$-based $\mathrm{LPEH}$ produces instantaneous maximum power of $8.2 \mathrm{~mW}$ and an energy density of $107.9 \mathrm{~mW} / \mathrm{cm}^{3}$ in a weak magnetic field of $250 \mu \mathrm{T}$. This system can be used to charge a capacitor and operate a wireless sensor network (WSN) system to provide temperature sensing and radio-frequency (RF) transmission in a $250 \mu \mathrm{T}$ magnetic field. The proposed LPEH is a promising green-energy device for potentially self-powering WSN systems when applied.
\end{abstract}

Keywords: piezoelectric energy harvester; AC magnetic field; lead-free material; sustainable energy; high energy conversion

\section{Introduction}

Self-driven energy harvesting technology, which concerns the gathering of energy from the environment, is attracting considerable research interest. Piezoelectric, electrothermal, triboelectric, and electromagnetic induction technologies are the main research areas in this field at present [1]. The power of energy harvesting technologies has been demonstrated by their role in providing large amounts of energy for the operation of wireless sensor networks (WSNs). Traditional use of commercial batteries has become unsuitable and impractical for applications such as WSNs, since their limited battery lifecycles and potential as environmental hazards become problems [2]. In contrast, piezoelectric energy harvesting offers high power-density levels and has a wide range of potential applications in the field [3]. A magnetic field represents an energy source that can be used in energy harvesting, with one example being that it can be used to generate vibrations. Electronic devices, power cables, and the magnetic fields generated by them have a frequency of $60 \mathrm{~Hz}$. However, it is difficult to harvest an electrical source from weak magnetic fields [4-6]. Piezoelectric materials generate electricity when they are subjected to vibration stress [7]. A permanent magnet can be used as a tip mass at the end of a cantilever and vibrations can be generated by a magnetic field, even in an energy harvester, in almost negligible magnetic fields $[8,9]$. Under these conditions, it will be necessary to improve the efficiency of piezoelectric materials to improve their energy-harvesting properties, particularly in low magnetic fields. Piezoelectric energy harvesting technology development will require material optimization efforts, including the development of high-quality piezoelectric compositions, mechanical optimization to enable more efficient conversion of the energy from the surrounding environment, and electrical optimization efforts to apply highefficiency electric circuit techniques to maximize the power transfer [10,11]. This will require a technical field that has fusion research involving both the mechanical and electrical 
spheres. Xing et al., were first proposed a multimode harvesting device based on a piezoelectric cantilever and a permanent magnet tip mass. At the time, this type of design was proven to have good performance at low frequencies. After that, Liu et al., designed a bimorph piezoelectric cantilever structure with PZT and NdFeB magnets, which obtained a maximum power density of $11.73 \mu \mathrm{W} / \mathrm{cm}^{3}$ for resonance excitations at $100 \mathrm{~Hz}$ and $100 \mu \mathrm{T}$ [12-14]. However, this level of performance is still difficult to put into commercial applications, faced with this challenge, this paper carried out a higher performance energy harvester research. The aim of the study presented here is therefore to develop a piezoelectric energy harvester that is capable of high power generation owing to its enhanced energy conversion constant $[15,16]$. In general, cantilever-type piezoelectric energy harvesters use bending vibration modes for electromechanical energy conversion. To improve the performance of a piezoelectric harvester that gathers electrical energy from ambient vibrations, it will be essential to improve the piezoelectric energy-conversion constant $\left(d_{33} \times g_{33}\right)$ through material optimization $[17,18]$. The high energy density of this type of piezoelectric material can be expressed using Equation (1), as follows.

$$
u=\frac{1}{2}\left(d_{33} \times g_{33}\right)\left(\frac{F}{A}\right)^{2}
$$

The performance of piezoelectric ceramics can be expressed using the energy conversion coefficient $\left(d_{33} \times g_{33}\right)$, which is obtained by multiplying the piezoelectric charge factor $\left(d_{33}\right)$ by the piezoelectric voltage factor $\left(g_{33}\right)$ in a manner identical to that used in energy-harvesting equations. This coefficient is an important performance index in many applications. To improve the performance of the piezoelectric energy harvester, a material composition with a high energy conversion constant $\left(d_{33} \times g_{33}\right)$ must be developed $[19,20]$. In a mechanical optimization process, we designed and manufactured a piezoelectric harvester with a high-output structure that is suitable for specific applications via multiphysics analysis $[21,22]$. In the electrical optimization process, we attempted to maximize the power density of this harvester using an impedance-matching technique, which is a type of maximum power transfer circuit technique [23,24]. To improve both the piezoelectric and dielectric properties of the materials, solid solutions are used at both the $\mathrm{A}$ and $\mathrm{B}$ sites of $\mathrm{BaTiO}_{3}$ (in general, $\mathrm{A}=\mathrm{Ca}, \mathrm{Sr}$, and $\mathrm{La}$, and $\mathrm{B}=\mathrm{Nb}, \mathrm{Ta}$, and $\mathrm{Zr}$ ) $[25,26]$. In particular, $\mathrm{Ca}^{2+}$ and $\mathrm{Zr}^{4+}$ doping has reportedly provided high piezoelectric coefficients $\left(d_{33}=620 \mathrm{pC} / \mathrm{N}\right)$ for $\mathrm{Ba}_{0.85} \mathrm{Ca}_{0.15} \mathrm{Ti}_{0.90} \mathrm{Zr}_{0.10} \mathrm{O}_{3}$ (BCTZ) [27]. Most studies have focused on control of the sintering temperature of the material and the roles of dopant and ion substitution to produce increases in the piezoelectric charge coefficient $(d)$ when using the same composition, although this is accompanied by changes in the BCTZ microstructure $[28,29]$. To develop a lead-free piezoelectric composition, the acceptor dopant ion $\mathrm{Cu}^{2+}$ is typically used to improve the output characteristics of piezoelectric materials and to reduce their sintering temperatures [30,31]. As a sintering aid, $\mathrm{CuO}$ can reduce sintering temperatures effectively, and it is also well known to improve the dense microstructure of these piezoelectric materials.

Thereout, we propose a high-performance lead-free piezoelectric energy harvester (LPEH) device based on a lead-free $\mathrm{Ba}_{0.85} \mathrm{Ca}_{0.15} \mathrm{Ti}_{0.90} \mathrm{Zr}_{0.10} \mathrm{O}_{3}+\mathrm{CuO} 0.3 \mathrm{wt} \%\left(\mathrm{BCTZC}_{0.3}\right)$ system. The LPEH fabricated in this work produces a high open-circuit voltage of approximately $104 \mathrm{~V}$ and instantaneous output power of $8.2 \mathrm{~mW}$ (power density: $107.9 \mathrm{~mW} / \mathrm{cm}^{3}$ ) with a load resistance of $10 \mathrm{k} \Omega$ during periodic motion changes that involve bending and unbending in a $250 \mu \mathrm{T}$ magnetic field. This LPEH device was connected to a capacitor to form power modules for use in self-powered systems under power-line cables. Furthermore, the power generated by a $250 \mu \mathrm{T}$ magnetic field is enough to operate a commercial WSN system. This achievement is unprecedented with regards to optimization of composite-based energy harvesters and represents an initial approach towards the use of lead-free piezoelectric composites in these devices. 


\section{Experimental}

Fabrication of a lead-free piezoelectric ceramic material: the lead-free $\mathrm{BCTZC}_{0.3}$ ceramic was produced using a conventional solid-state reaction method. The powders used were weighed. $\mathrm{BaCO}_{3}\left(99.0 \%\right.$, CAS No.513-77-9, Daejung, Korea), $\mathrm{CaCO}_{3}(99.0 \%$, Lot No. 2018A1662, JUNSEI, Japan), $\mathrm{TiO}_{2}$ (99.0\%, Lot No. 2018B1266, JUNSEI, Japan), $\mathrm{ZrO}_{3}$ (99.0\%, CAS No.1314-23-4, Daejung, Korea), and $\mathrm{CuO}$ (99.9\%), were mixed via ball milling in alcohol for $24 \mathrm{~h}$. After drying, the mixture was calcined in an alumina crucible at $1250{ }^{\circ} \mathrm{C}$ for $2 \mathrm{~h}$. The calcined powder was then milled for another $12 \mathrm{~h}$. The dried powder was subsequently mixed with $2 \%$ polyvinyl alcohol (PVA) and made into a bulk disk form at a pressure of $100 \mathrm{MPa}$. The green disk was then sintered in air at $1300-1450{ }^{\circ} \mathrm{C}$ for $2 \mathrm{~h}$ and the sintered bulk surface was subsequently polished before the measurements were performed. The calcined powder was again mixed with a plasticizer (B-73225, FERRO, USA) and polyvinyl butyral resin (PVB) as a polymer for $24 \mathrm{~h}$ to prepare a slurry with a ceramic-to-polymer relative weight ratio of 2:1. The slurry was then deformed in a vacuum for 30 min to remove any bubbles. A green sheet with a thickness of approximately $30 \mu \mathrm{m}$ was prepared using the finished slurry via a tape casting process. A square sample with dimensions of $30 \times 40 \mathrm{~mm}^{2}$ was prepared using a cutter (DC-5, DH) and the sheets were laminated on a layer-by-layer basis. In total, ten green sheets were laminated for $10 \mathrm{~min}$ at $60{ }^{\circ} \mathrm{C}$ under a pressure of $10 \mathrm{~kg}$ in each case. To remove the organic additives from the laminated sheet, the specimens were heated slowly to $600{ }^{\circ} \mathrm{C}$ and held at that temperature for $3 \mathrm{~h}$ in an electric furnace (AJ-MLBF2, AJEON). To allow the film to undergo poling, an electric field was applied to the sintered thick film for $2 \mathrm{~h}$ at $2 \mathrm{kV} / \mathrm{mm}$.

Characterization of the lead-free piezoelectric ceramic material: field emissionscanning electron microscope (FE-SEM) imaging and an energy dispersive spectroscopy (EDS) mapping analysis were performed using a Verios 460L SEM. The crystalline phase and orientation were analyzed via high-resolution X-ray diffraction (XRD) (HR-XRD; ATX-G, Rigaku Co.) and X-ray photoelectron spectroscopy (XPS) spectroscopy (Invia Raman Microscope, Renishaw) measurements. The piezoelectric charge constant $\left(d_{33}\right)$ was measured using a $d_{33}$ meter (PM100, Piezotest), and the piezoelectric and dielectric properties were determined using an impedance analyzer (HP4194A Hewlett Packard) using IEEE standards.

Measurement of energy-harvesting properties: The $\mathrm{BCTZC}_{0.3}$ films were attached to the top of a stainless-steel substrate (SUS304) and were tested using an oscilloscope (Tektronix, DPO4054B) to evaluate their power-generation characteristics with a shaker (Brûel \& Kjær, 4809) and a high-speed bipolar amplifier (NF, HSA4014). The amplifier was driven by a function generator (Agilent, 33220A) and the shaker provided periodic excitation with a harmonic signal. To produce a magnetic field on the LPEH, an AC magnetic field was applied to the harvesters using a Helmholtz coil. The harvesters in the magnetic field were measured in a frequency range of 30 to $90 \mathrm{~Hz}$ using a function generator (Agilent, 33220A). The samples were collected as a function of the applied DC magnetic field from 0-250 $\mu \mathrm{T}$ using a high-speed bipolar amplifier (NF, HSA4014) in a fixed AC magnetic field at $60 \mathrm{~Hz}$ (their resonance frequency). Energy harvesting through the fabricated LPEH was demonstrated around the power-line cable of an automatic voltage regulator $(30 \mathrm{kV}, 60 \mathrm{~Hz})$, which was used as the magnetic field source.

\section{Results and Discussion}

To demonstrate a high energy conversion device, $\mathrm{BCTZC}_{0.3}$-based lead-free piezoelectric ceramic comparable to the PZT-based piezoelectric ceramic served as an active material. For the magnetic field phase, a magnetic metal was used as the tip mass. A magnetic tip mass is advantageous for promoting improved energy-harvesting performance in a weak $\mathrm{AC}$ magnetic field, and the $\mathrm{BCTZC}_{0.3}$ film composite fabricated on a spring-metal substrate had achieved a high output voltage coefficient in previous work. The LPEH consisted of a high energy conversion material and a magnetic tip mass, as shown in Figure 1a. The high energy conversion property of the LPEH in a weak magnetic field 
range contributed to improved energy harvesting performance by the composite. The magnetoelectric effect in the LPEH results in the conversion of the magnetic field to mechanical strain, which is then converted to an electric charge through the lead-free $\mathrm{BCTZC}_{0.3}$. To realize a magnetoelectric harvester operating at $60 \mathrm{~Hz}$, the piezoelectric energy material $\left(1.9 \times 1.6 \times 0.25 \mathrm{~cm}^{3}\right)$ was attached to a spring-metal substrate $\left(4.0 \times 9.0 \times 0.02 \mathrm{~cm}^{3}\right)$ as the LPEH, as shown in Figure 1b. The inset indicates the piezoelectric active material when sintered at $1450{ }^{\circ} \mathrm{C}$. The energy-harvesting performance contribution of the sintering temperature on the LPEH is demonstrated in Figure 3i. In order to improve the lead-free piezoelectric energy-harvesting performance in a weak magnetic field, the energy conversion of the LPEH was increased by changing the sintering temperature. To design the optimum piezoelectric energy-harvesting composition, $\mathrm{BCTZC}_{0.3}$ ceramics with improved power conversion constant $\left(d_{33} \times g_{33}\right)$ values were fabricated. These $\mathrm{BCTZC}_{0.3}$ samples were sintered at various temperatures ranging from 1300 to $1450{ }^{\circ} \mathrm{C}$. Figure $1 \mathrm{c}$ shows the results of an X-ray diffraction (XRD) analysis of the sintering temperatures that were utilized to investigate the optimum composition of the $\mathrm{BCTZC}_{0.3}$ samples. Rhombohedral crystals with a perovskite structure and without a secondary phase were observed for the $\mathrm{BCTZC}_{0.3}$ depending on the sintering temperature. As the sintering temperature was increased from 1300 to $1450{ }^{\circ} \mathrm{C}$, the (110) peak intensity also showed a comparative increase. This outcome is closely related to the increase in grain size, as observed in the field emission-scanning electron microscope (FE-SEM) images indicated in Figure $1 \mathrm{~d}$. For the $\mathrm{BCTZC}_{0.3}$ sample that was sintered at $1500{ }^{\circ} \mathrm{C}$, even if the (200) intensity increased, the (110) intensity decreased. This was observed as the melting phenomenon progressed. Figure $1 \mathrm{~d}$ shows surface images of the $\mathrm{BCTZC}_{0.3}$ samples with changes in the sintering temperatures. The $\mathrm{BCTZC}_{0.3}$ samples that were sintered at $1350{ }^{\circ} \mathrm{C}$ show various grain sizes ranging from 5 to $10 \mu \mathrm{m}$, and these grains grew from $20 \mu \mathrm{m}$ to more than $100 \mu \mathrm{m}$. Hence, the grain size increased considerably when the sintering temperature was increased to $1450{ }^{\circ} \mathrm{C}$. With the sample sintered at $1500{ }^{\circ} \mathrm{C}$, the surfaces melted due to the high sintering temperature and the piezoelectric and dielectric properties could not be measured (see Supporting Information Figures S3-S5). Figure 1e shows the results of an X-ray photoelectron spectroscopy (XPS) analysis of the $\mathrm{BCTZC}_{0.3}$ sample sintered at $1450{ }^{\circ} \mathrm{C}$. $\mathrm{Ba}, \mathrm{Ti}, \mathrm{Ca}$, and $\mathrm{Zr}$ components were detected, whereas no secondary phase corresponding to $\mathrm{CuO}$ was detected. Furthermore, the $\mathrm{Ba}, \mathrm{Ca}, \mathrm{Ti}, \mathrm{Zr}$, and $\mathrm{Cu}$ atoms were homogeneously dispersed on the surface of the $\mathrm{BCTZC}_{0.3}$ sample, as in the energy dispersive spectrometer (EDS) mapping images in Figure 1f.

Figure 2 shows the piezoelectric and dielectric properties of the $\mathrm{BCTZC}_{0.3}$ samples with respect to the sintering temperature used. As the sintering temperature was increased, the material density generally increased in all $\mathrm{BCTZC}_{0.3}$ samples. The conversion efficiency $(\eta)$ exceeded $82 \%$ in all sintered samples. As the sintering temperature was increased, the conversion constant $\left(k_{p}\right)$ also generally increased, but the value of the quality factor $\left(Q_{m}\right)$ decreased. The piezoelectric voltage constant $\left(g_{33}\right)$ also showed an improvement, caused by the increases in both the piezoelectric charge constant $\left(d_{33}\right)$ and the relative dielectric constant. The piezoelectric voltage constant $\left(g_{33}\right)$ can be determined using the equation $\left(g_{33}=d_{33} /\right.$ dielectric constant $)$. The dielectric constant tends to decrease as the sintering temperature increases to more than $1400^{\circ} \mathrm{C}$, which then leads to an improvement in the piezoelectric voltage constant. Because this piezoelectric voltage constant improved, the $\mathrm{BCTZC}_{0.3}$ sample that was sintered at $1450{ }^{\circ} \mathrm{C}$ had a high power-conversion constant. This phenomenon is related to both the grain growth and the increased intensity of the (110)oriented crystal. Table 1 presents the values of the piezoelectric and dielectric characteristics of the samples based on various sintering temperatures. The $\mathrm{BCTZC}_{0.3}$ specimen sintered at $1450{ }^{\circ} \mathrm{C}$ has a high piezoelectric charge constant $\left(d_{33}\right)$ of $526 \mathrm{pC} / \mathrm{N}$, a conversion constant $\left(k_{p}\right)$ of $49.3 \%$, and a high power conversion constant $\left(d_{33} \times g_{33}\right)$ of $15,780 \times 10^{-15} \mathrm{~m}^{2} / \mathrm{N}$. Therefore, we used the $\mathrm{BCTZC}_{0.3}$ sample sintered at $1450{ }^{\circ} \mathrm{C}$ as the active material of the LPEH. 

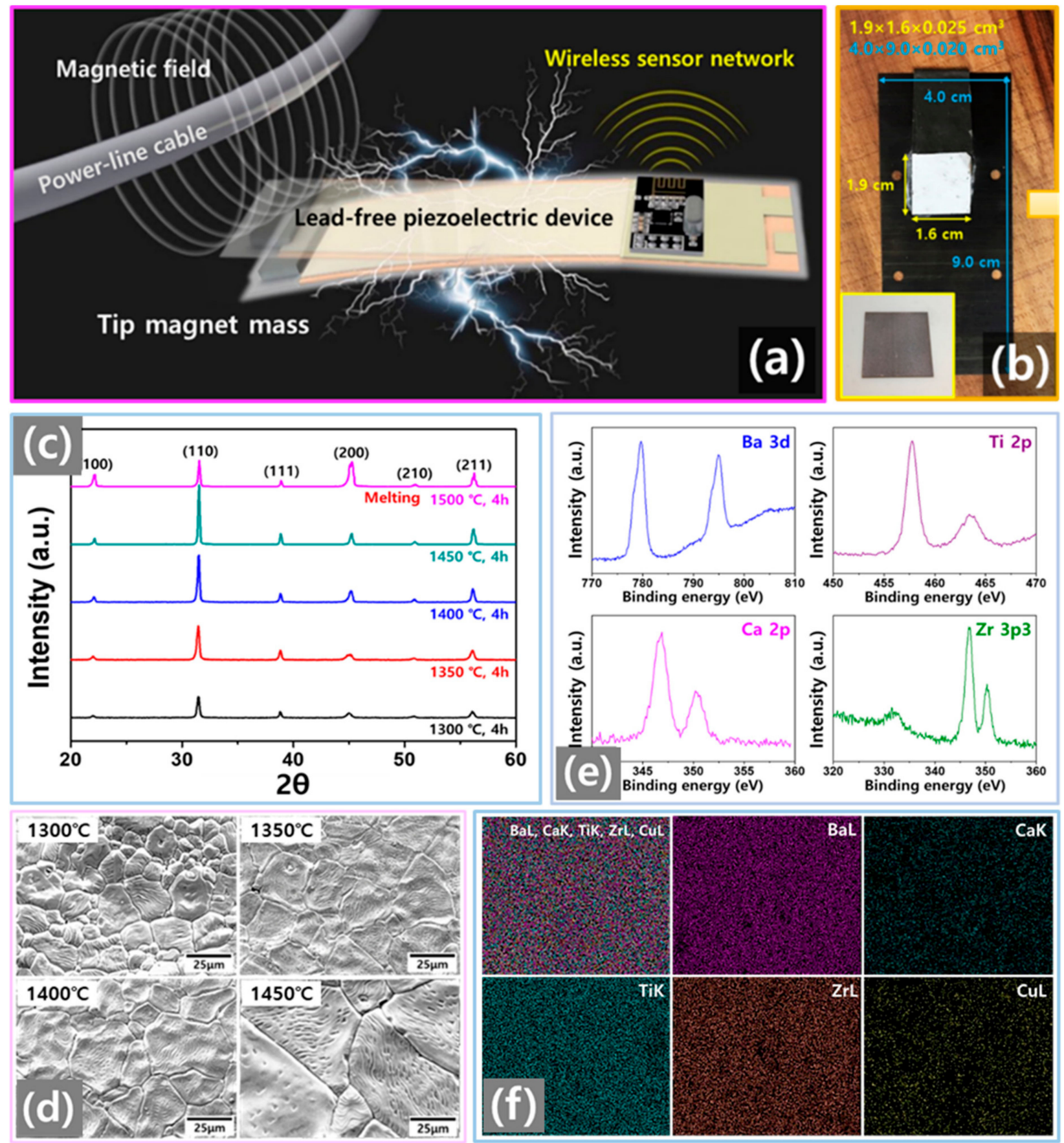

Figure 1. (a) Schematic of magnetic field energy harvesting using a lead-free piezoelectric device for a wireless sensor network. (b) Photograph of the lead-free piezoelectric energy harvester (LPEH) device, with the inset showing the piezoelectric film of $\mathrm{BCTZC}_{0.3}$ sintered at $1450{ }^{\circ} \mathrm{C}$. (c) $\mathrm{XRD}$ graphs of $\mathrm{BCTZC}_{0.3}$ ceramics sintered at various temperatures. (d) Surface field emission-scanning electron microscope (FE-SEM) images of the $\mathrm{BCTZC}_{0.3}$ ceramics sintered at different temperatures. (e) X-ray photoelectron spectroscopy (XPS) component analysis graphs of the $\mathrm{BCTZC}_{0.3}$ ceramic sintered at $1450{ }^{\circ} \mathrm{C}$. (f) Energy dispersive spectra (EDS) mapping analysis of the $\mathrm{BCTZC}_{0.3}$ composites. 


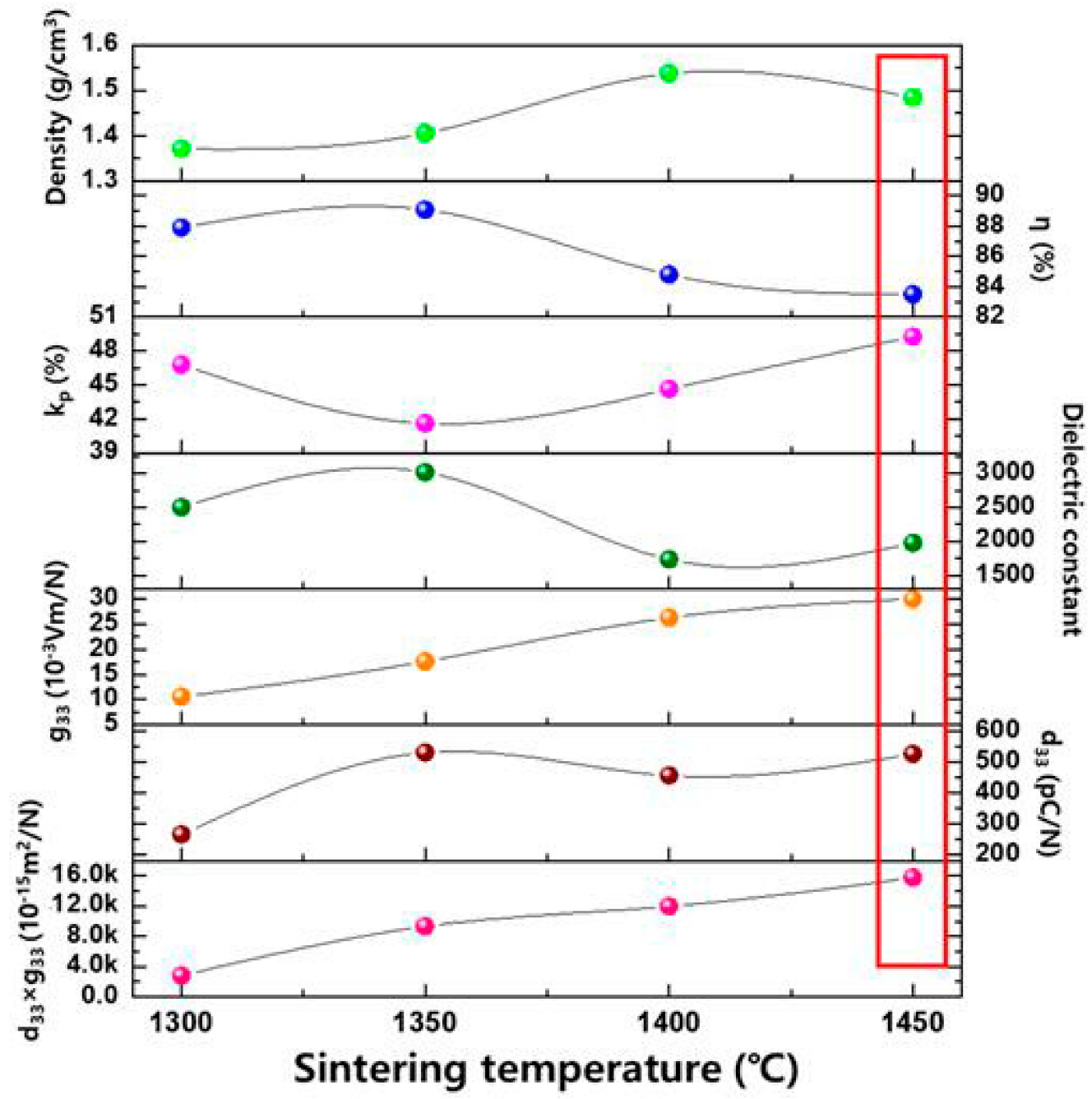

Figure 2. Piezoelectric and dielectric properties of the $\mathrm{BCTZC}_{0.3}$ ceramics sintered at various temperatures.

Table 1. Piezoelectric and dielectric properties of $\mathrm{BCTZC}_{0.3}$ samples according to their sintering temperatures.

\begin{tabular}{|c|c|c|c|c|c|c|c|}
\hline $\begin{array}{c}\text { Sintering } \\
\text { Temperature } \\
\left({ }^{\circ} \mathrm{C}\right)\end{array}$ & $\begin{array}{l}\text { Dielectric } \\
\text { Constant }\end{array}$ & $\begin{array}{l}\text { Density } \\
\left(\mathrm{g} / \mathrm{cm}^{3}\right)\end{array}$ & $d_{33}(\mathrm{pC} / \mathrm{N})$ & $\begin{array}{c}g_{33} \\
\left(10^{-3} \mathrm{Vm} / \mathrm{N}\right)\end{array}$ & $k_{p}(\%)$ & $\begin{array}{c}d_{33} \times g_{33} \\
\left(10^{-15} \mathrm{~m}^{2} / \mathrm{N}\right)\end{array}$ & Efficiency $(\eta)$ \\
\hline 1300 & 2500.4 & 1.37 & 265 & 10.6 & 46.8 & 2809 & 0.88 \\
\hline 1350 & 3016.6 & 1.40 & 530 & 17.6 & 41.6 & 9322 & 0.89 \\
\hline 1400 & 1734.3 & 1.54 & 456 & 26.3 & 44.6 & 11,990 & 0.85 \\
\hline 1450 & 1976.2 & 1.48 & 526 & 30.0 & 49.3 & 15,780 & 0.84 \\
\hline
\end{tabular}

Table 2 shows the output signals from the LPEH and other previously reported piezoelectric energy harvesters, along with values pertaining to the acceleration $\left(\mathrm{m} / \mathrm{s}^{2}\right)$, resonance frequencies $(\mathrm{Hz})$, and energy-conversion constants of these harvesters. Among the PZT series devices the energy-conversion constant is $9.3 \mathrm{k}$ when using bulk PZT-5A, and the corresponding output power and power density are $40 \mu \mathrm{W}$ and $0.38 \mu \mathrm{W} / \mathrm{mm}^{3}$, respectively. The maximum output power was observed when using the PZT-CN material, which had a high piezoelectric conversion constant of $14 \mathrm{k}$, a maximum output power of $17,300 \mu \mathrm{W}$, and power density of $2.08 \mu \mathrm{W} / \mathrm{mm}^{3}$ at its resonance frequency of $20 \mathrm{~Hz}$. When using the lead-free piezoelectric materials of KNNS bulk, the output power was less than $20 \mu \mathrm{W}$ while the resonance frequency exceeded $70 \mathrm{~Hz}$. The BCTZ bulk generated output power of $70 \mu \mathrm{W}$ at $90 \mathrm{~Hz}$ under acceleration of $10 \mathrm{~m} / \mathrm{s}^{2}$ [32-39]. The BCTZC0.3 shows a maximum output power of $8200 \mu \mathrm{W}$ and an energy density of $107.9 \mu \mathrm{W} / \mathrm{mm}^{3}$. 
However, it was developed with reference to the vibration conditions, with a resonance of $60 \mathrm{~Hz}$ and a low acceleration, $2.0 \mathrm{~m} / \mathrm{s}^{2}$, when compared with many of the harvesters in the other studies. The excellent output characteristics generated using the BCTZC0.3 materials were realized by the stable crystal formation of the highly (110)-oriented crystal. This material can thus serve as the basis for a reliable and sustainable high-performance energy harvester.

Table 2. The output signals from the LPEH and other previously reported piezoelectric energy harvesters.

\begin{tabular}{|c|c|c|c|c|c|c|}
\hline Material & $\begin{array}{c}d_{33} \times g_{33} \\
\left(10^{-15} \mathrm{~m}^{2} / \mathrm{N}\right)\end{array}$ & $\begin{array}{l}\text { Frequency } \\
\text { (Hz) }\end{array}$ & $\begin{array}{l}\text { Acceleration } \\
\left(\mathrm{m} / \mathrm{s}^{2}\right)\end{array}$ & Power $(\mathrm{mW})$ & $\begin{array}{l}\text { Power Density } \\
\left(\mathrm{mW} / \mathrm{cm}^{3}\right)\end{array}$ & Ref. \\
\hline PZT-5A bullk & $9.3 \mathrm{k}$ & 36 & 2 & 0.040 & 0.38 & [30] \\
\hline $\mathrm{PZN}-\mathrm{PZT}+\mathrm{MnO}_{2}$ & - & 90 & 10 & 0.098 & 1.5 & [31] \\
\hline PZT-5H bulk & $11.7 \mathrm{k}$ & 40 & - & 0.11 & 3.82 & [32] \\
\hline PZT-CN & $14 \mathrm{k}$ & 20 & - & 0.11 & 3.82 & [32] \\
\hline This work (BCTZ0.3C) & $15.8 \mathrm{k}$ & 60 & - & 82 & 107.9 & - \\
\hline KNNS bulk & - & 70 & 7 & 0.008 & 0.01 & [34] \\
\hline BS-PT bulk & - & 41 & 10 & 0.013 & 0.08 & [35] \\
\hline CNKN bulk & $4.9 \mathrm{k}$ & 93 & - & - & 12 & [36] \\
\hline BCTZ bulk & - & 90 & 10 & 0.07 & 1.4 & [37] \\
\hline
\end{tabular}

The experimental setup that was used to measure the output power and the displacement generated via piezoelectric energy harvesting driven by a Helmholtz coil is shown in Figure 3a. The LPEH has a tip magnet that indicates the energy harvester response of the designed cantilever structure. It has a permanent $\mathrm{Nd}$ magnet at its tip, which bends when an external magnetic AC field at $60 \mathrm{~Hz}$ is applied. The field is generated using the Helmholtz coils. Using a power amplifier and a function generator, the magnetic field of the Helmholtz coil was adjusted over the range of 140-250 $\mu \mathrm{T}$ and the magnetic field generated was measured using a tesla meter. In Figure 3b, these LPEHs were generated at various frequency conditions of the maximum power-generation characteristics of the $\mathrm{BCTZC}_{0.3}$ films at a sintering temperature of $1450{ }^{\circ} \mathrm{C}$. To measure the resonance frequencies $(\mathrm{Hz})$ of the fabricated LPEHs, we used Equation (2) with the following terms: $E=$ Young's modulus; $L=$ beam length; $I=$ moment of inertia; and $m=$ tip mass. The physical properties of the LPEH (e.g., its length, mass, area, thickness, and Young's modulus) determine its operational performance. The LPEH was designed to be tuned for a resonance frequency of $60 \mathrm{~Hz}$. The calculated LPEH resonance frequency was about $60 \mathrm{~Hz}$ : $E=6.3 \mathrm{GPa}, L=9 \times 10^{-2} \mathrm{~m}, I=1.1 \times 10^{-10} \mathrm{~m}^{4}$, and $m=20 \mathrm{~g}$.

$$
f_{r}=\frac{1}{2 \pi} \sqrt{\frac{3 E I}{L^{3} m}}
$$

The minimum output voltage $(\mathrm{V})$ of the $\mathrm{LPEH}$ with the $\mathrm{BCTZC}_{0.3}$ film sintered at $1450{ }^{\circ} \mathrm{C}$ was $2.2 \mathrm{~V}_{\mathrm{OC}}$ at a frequency of $72 \mathrm{~Hz}$, while the maximum output voltage was $6.3 \mathrm{~V}$ at a frequency of $60 \mathrm{~Hz}$. The maximum displacement of the tip mass of the LPEH was found to be $2.4 \mathrm{~cm}$ at a frequency of $60 \mathrm{~Hz}$. Figure 3d shows graphs of the LPEHs measured in terms of the electrical energy according to different magnetic fields $(140-250 \mu \mathrm{T})$. The peak of the output voltage gradually improved as the magnetic field was increased to $250 \mu \mathrm{T}$. The maximum output voltage value was $6.3 \mathrm{~V}_{\mathrm{OC}}$ at a magnetic field of $250 \mu \mathrm{T}$. Figure $3 \mathrm{e}$ shows the results of simulations of the piezoelectric potential and voltage shapes during bending and unbending trials of the piezoelectric energy harvester, as determined using the ATILA software package. (Atila is a commercially available finite element analysis (FEA) software package developed specifically for the modeling and analysis of devices made of piezoelectric or magnetostrictive materials. The simulation study was conducted using ATILA (version 6.0.0.6) finite element analysis (FEA) software with a pre and postGID (version 10.0.9) processor) [40,41]. A positive piezoelectric voltage is generated from compressive stress between the two electrodes when downward mechanical stress is 
applied. Otherwise, upward stress would lead to the generation of negative voltage from the tensile pressure. We can assume that the negative voltage and positive voltage outputs generated in the energy harvester are related to the direction in which the stress is applied. Figure $3 \mathrm{f}$ shows the open-circuit output voltage signals obtained from the LPEHs with the $\mathrm{BCTZC}_{0.3}$ films when plotted according to their sintering temperatures. The open-circuit output voltage also increases as the sintering temperature increases; the instantaneous maximum output voltage is $6.3 \mathrm{~V}_{\mathrm{OC}}$ at $1450{ }^{\circ} \mathrm{C}$ and the minimum output voltage is $2.65 \mathrm{~V}_{\mathrm{OC}}$ at $1300{ }^{\circ} \mathrm{C}$. A mechanical durability experiment was performed to evaluate the practical applicability of the proposed LPEH. Figure $3 \mathrm{~g}$ shows the results of output voltage measurements by the LPEH, demonstrating electromechanical stability for over 216,000 cycles for $60 \mathrm{~min}$ with bending displacement of $2 \mathrm{~cm}$. As an indicated in Figure $3 \mathrm{~h}$, the instantaneous maximum output powers of the LPEHs with the $\mathrm{BCTZC}_{0.3}$ films sintered at various temperatures are dependent on the load resistance over the range of $100 \Omega$ to $100 \mathrm{k} \Omega$. To measure the output power $(\mathrm{P})$, the peak value of the output voltage (V) applied to the load resistance (R) divided by this load resistance (R) is used in the following equation: $\mathrm{P}=\mathrm{V}^{2} / \mathrm{R}$. The output power $(\mathrm{mW})$ increases steadily with an increase in the sintering temperature from 1300 to $1450{ }^{\circ} \mathrm{C}$. The minimum output power of the $\mathrm{LPEH}$ with the $\mathrm{BCTZC}_{0.3}$ sintered at $1300{ }^{\circ} \mathrm{C}$ is $4.0 \mathrm{~mW}$, while the maximum output power of the LPEH with the $\mathrm{BCTZC}_{0.3}$ sintered at $1450{ }^{\circ} \mathrm{C}$ is $8.2 \mathrm{~mW}$. To measure the power density of each $\mathrm{LPEH}$, the output power $(\mathrm{P})$ and the volume $\left(\mathrm{cm}^{3}\right)$ of the $\mathrm{BCTZC}_{0.3}$ film were used in the following equation: power density $=\mathrm{P} /$ volume. The minimum power density $\left(\mathrm{mW} / \mathrm{cm}^{3}\right)$ of the LPEH with the $\mathrm{BCTZC}_{0.3}$ film that was sintered at $1300{ }^{\circ} \mathrm{C}$ was $52.63 \mathrm{~mW} / \mathrm{cm}^{3}$, while the maximum power density of the $\mathrm{LPEH}$ with the $\mathrm{BCTZC}_{0.3}$ that was sintered at $1450{ }^{\circ} \mathrm{C}$ was $107.9 \mathrm{~mW} / \mathrm{cm}^{3}$. The energy-conversion constant $\left(d_{33} \times g_{33}\right)$ values of the $\mathrm{BCTZC}_{0.3}$ samples with their sintering temperatures are closely related to the output power $(\mathrm{mW})$ of the LPEH. Figure $3 i$ presents graphs of the energy-conversion constants $\left(d_{33} \times g_{33}\right)$ and the output power $(\mathrm{mW})$ levels of BCTZC $_{0.3}$ films with respect to the sintering temperature. The inset shows the lighting of 30 white light-emitting diodes (LEDs). The graphs of the energy-conversion constant $\left(d_{33} \times g_{33}\right)$ and the output power $(\mathrm{mW})$, show similar trends. For LPEHs using the $\mathrm{BCTZC}_{0.3}$ films, an increase in the energy-conversion constant $\left(d_{33} \times g_{33}\right)$ was found to factor into the improvement of the $\mathrm{LPEH}$ output power $(\mathrm{mW})$. The $\mathrm{LPEH}$ with the $\mathrm{BCTZC}_{0.3}$ sintered at $1450{ }^{\circ} \mathrm{C}$ was selected for use as a power source in self-powering WSNs. These results clearly indicate that an energy harvester with a suitably high energy-conversion constant can convert energy in environments characterized by weak magnetic fields into a usable form of electrical energy. The output signals from the LPEH and other previously reported piezoelectric energy harvesters are indicated in Table 2.

Figure 4a,b illustrates a promising application of the energy harvester, which is used to operate a WSN using the output voltage generated by the LPEH. The WSN system consists of a bridge rectifier, a capacitor, a step-down converter, a temperature sensor, $2.4 \mathrm{GHz}$ wireless transmission, and a wireless receiver (with photographs of the WSN system components). The AC voltage generated by the LPEH was converted into DC voltage using the rectifier. To supply electric power stably, the capacitor was charged to supply the required power using DC voltage. Using the step-down converter, the supplied power is constantly reduced to enable the operation of both the temperature sensor and the wireless transmitter, and the data pertaining to the ambient temperature is transmitted to a computer. To verify the feasibility of the use of lead-free generators in practical applications, it was also necessary to evaluate the operation of the WSN system. Figure 4c presents the LPEH performance results after the successful charging of the capacitor (capacitance: $150 \mu \mathrm{F}$ ) up to $6.5 \mathrm{~V}$ over $2.8 \mathrm{~min}$ in a field of $250 \mu \mathrm{T}$. The energy generated by the harvester from the mechanical energy was used successfully to drive both a temperature sensor and a radio frequency transmitter using electricity that was first stored in a capacitor. The energy harvester generated the output voltage required to operate the WSN system in a magnetic field of $250 \mu \mathrm{T}$. The capacitor was 
charged to $6.5 \mathrm{~V}$ in $2.8 \mathrm{~min}$ and was then able to supply sufficient energy to drive the WSN system to measure the ambient temperature and transmit the measured data to a computer every $0.8 \mathrm{~min}$. The LPEH device could also be used in bending and unbending applications with a magnetic field to operate the WSN system. The energy-harvesting system is capable of real-time sensing, based on transmissions to the WSN system, of the power generated from the AC magnetic field condition. This lead-free $\mathrm{BCTZC}_{0.3}$ with a high energy-conversion constant can transmit the temperature data wirelessly to a notebook computer. Self-powered WSN technologies combined with a real-time monitoring and management system require further investigation of lead-free piezoelectric energy device systems in advanced electronics.
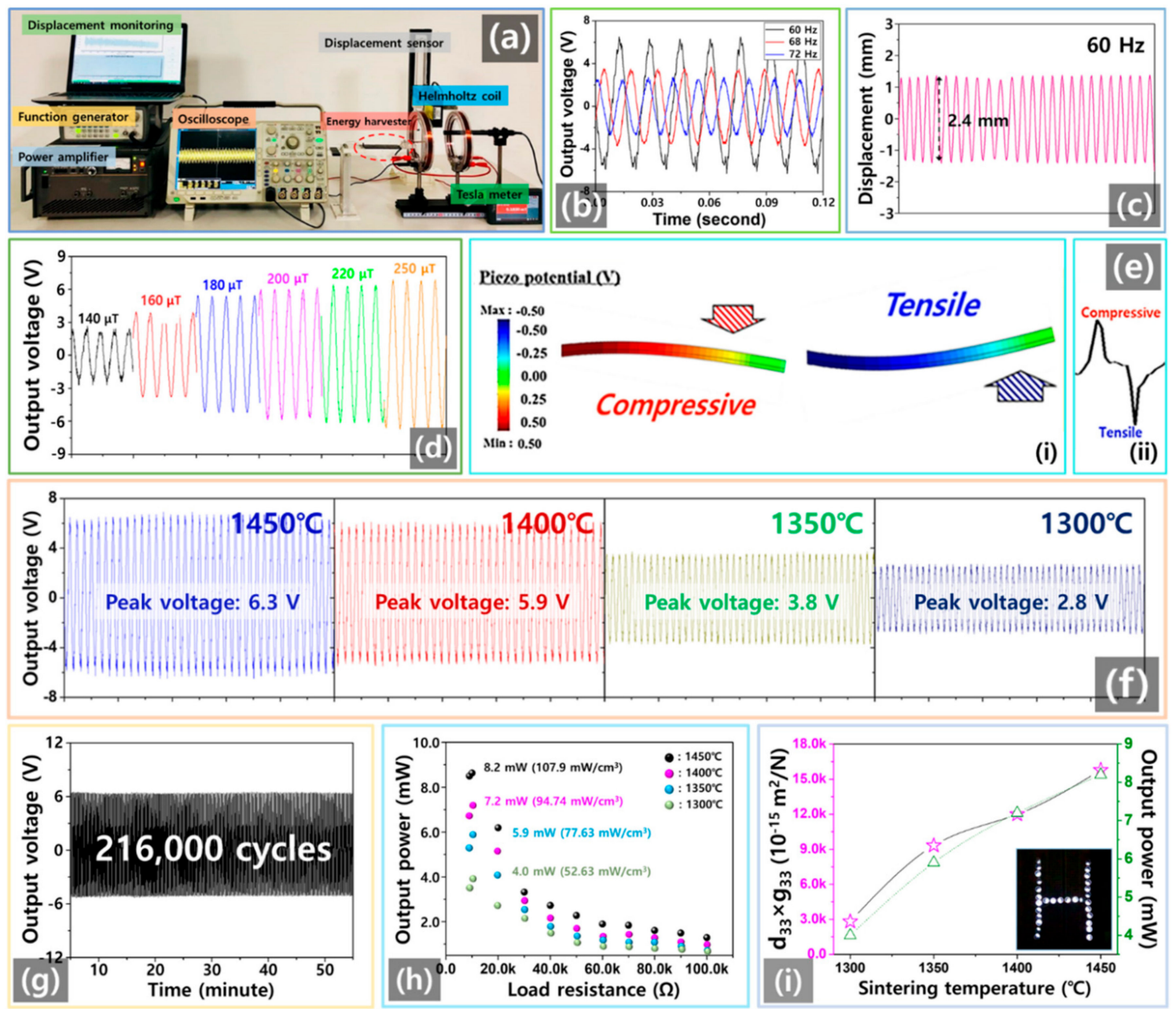

Figure 3. (a) Photograph of the experimental environment used to observe the power-generation characteristics of the LPEH in various magnetic fields $(\mu \mathrm{T})$. (b) Open-circuit output voltage $(\mathrm{V})$ of the LPEH at various frequencies. (c) Displacement of the LPEH at a resonance frequency of $60 \mathrm{~Hz}$. (d) Open-circuit output voltage (V) of the LPEH in differential magnetic fields $(\mu \mathrm{T})$. (e) Simulated data of the piezoelectric potential $(\mathrm{V})$ when stress is applied. (f) Open-circuit output voltage (V) characteristics of LPEHs composed of $\mathrm{BCTZC}_{0.3}$ films processed at various sintering temperatures $\left({ }^{\circ} \mathrm{C}\right)$. (g) Opencircuit output voltage of the LPEH for a durability test of over 216,000 cycles performed in a magnetic field of $250 \mu \mathrm{T}$. (h) Instantaneous maximum output power $(\mathrm{mW})$ values of $\mathrm{LPEHs}$ with $\mathrm{BCTZC}_{0.3}$ films sintered at various temperatures $\left({ }^{\circ} \mathrm{C}\right)$ under specific load resistances $(\Omega)$ for impedance matching. (i) Power conversion constant $\left(d_{33} \times g_{33}\right)$ and instantaneous maximum output power $(\mathrm{mW})$ values of $\mathrm{LPEHs}$ with $\mathrm{BCTZC}_{0.3}$ films, depending on their sintering temperatures $\left({ }^{\circ} \mathrm{C}\right)$. The inset shows lighting when using 30 white light-emitting diodes. 

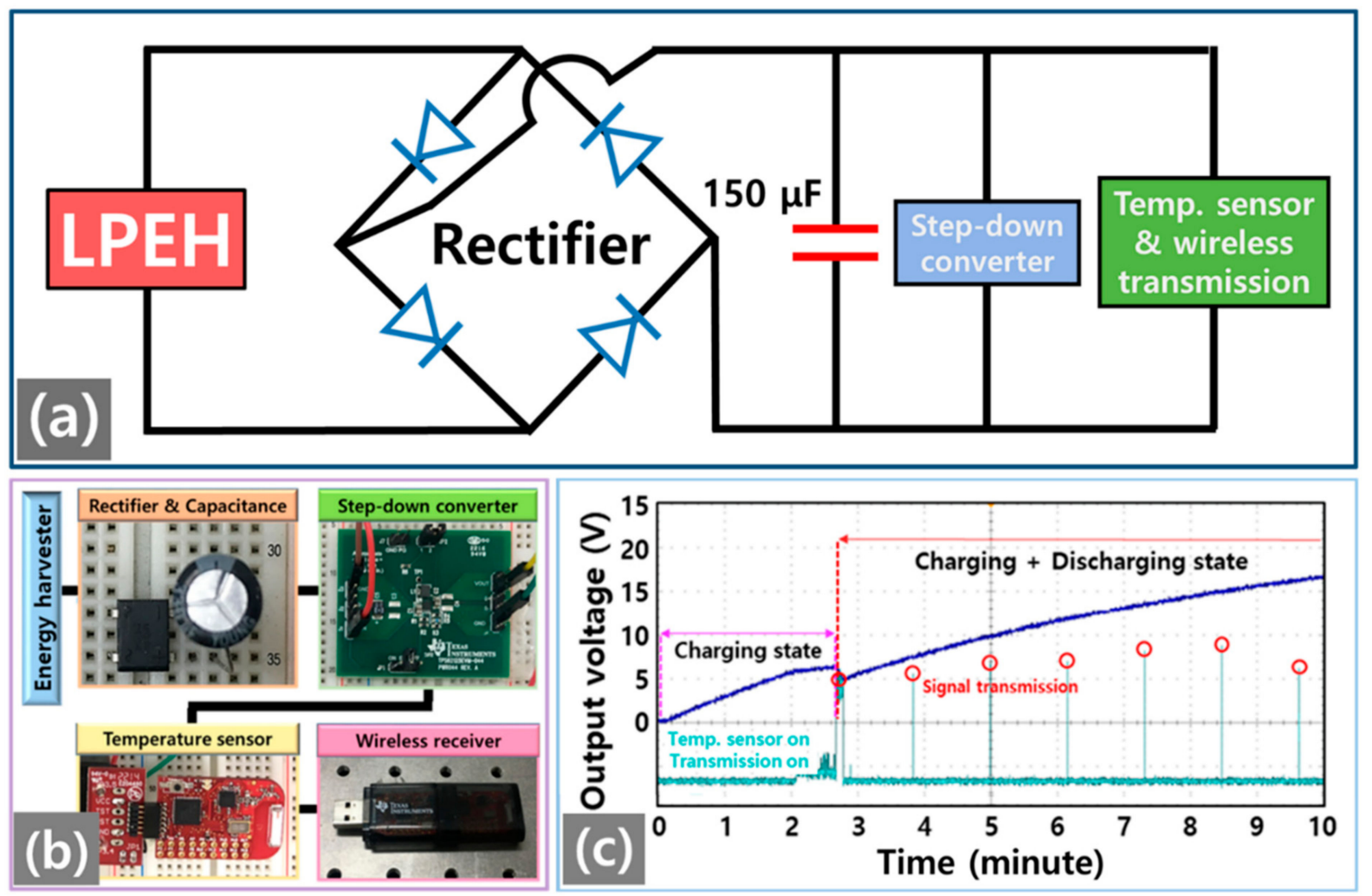

Figure 4. (a) Circuit diagram of self-powered wireless temperature monitoring system powered with the LPEH in a magnetic field of $250 \mu \mathrm{T}$. (b) Photograph images of the self-powered wireless temperature monitoring system (see Supporting Information Figures S1 and S2). (c) Characteristics of the self-charging voltage that drives the temperature sensor and radio-frequency (RF) transmission using a capacitor of $150 \mu \mathrm{F}$ with the LPEH in a magnetic field of $250 \mu \mathrm{T}$.

Figure 5a shows the experimental environment that was used to harvest electrical energy from the power-line cable of an automatic voltage regulator $(30 \mathrm{kV})$. During operation of the automatic voltage regulator, we measured the LPEH's electrical output performance. An energy-harvesting circuit diagram is presented in Figure $5 \mathrm{~b}$. For the automatic voltage regulator operation period, the output voltages were fixed at approximately $1.36 \mathrm{~V}_{\max }$ and $0.87 \mathrm{~V}_{\mathrm{rms}}$, shown in Figure $5 \mathrm{c}$. Vertical displacement was generated by the LPEH at $60 \mathrm{~Hz}$ in a weak magnetic field of $78 \mu \mathrm{T}$. Total displacement of $0.8 \mathrm{~mm}$ was generated from the change in the magnetic force acting between the magnets of the LPEH. Figure $5 \mathrm{~d}$ indicates that the LPEH generated an output voltage signal when the regulator was turned on and off. With regard to the regulator's turn on step, the voltage signal was instantaneously increased to $1.8 \mathrm{~V}$ as overcurrent. When the regulator operated normally, the output voltage was generated constantly. When the regulator was turned off, the voltage signal level decreased abruptly. To demonstrate the durability of the proposed LPEH, the output performance was tested over a period of 216,000 cycles, with the results shown in Figure 5e. This verified that the magnetic-force-based power-generation mechanism of the LPEH offers high stability and an output voltage of approximately $1.32 \mathrm{~V}$. This phenomenon can be attributed to confirmation of the development of the proposed BCTZC $_{0.3}$-based LPEH as an energy source from weak magnetic fields. The output power from this lead-free piezoelectric energy harvester was $1.52 \mathrm{~mW}$ at load resistance of $7 \mathrm{k} \Omega$ in Figure 5f. These results fully demonstrate that the LPEH based on the BCTZC ${ }_{0.3}$ film could provide a reliable source of energy. 

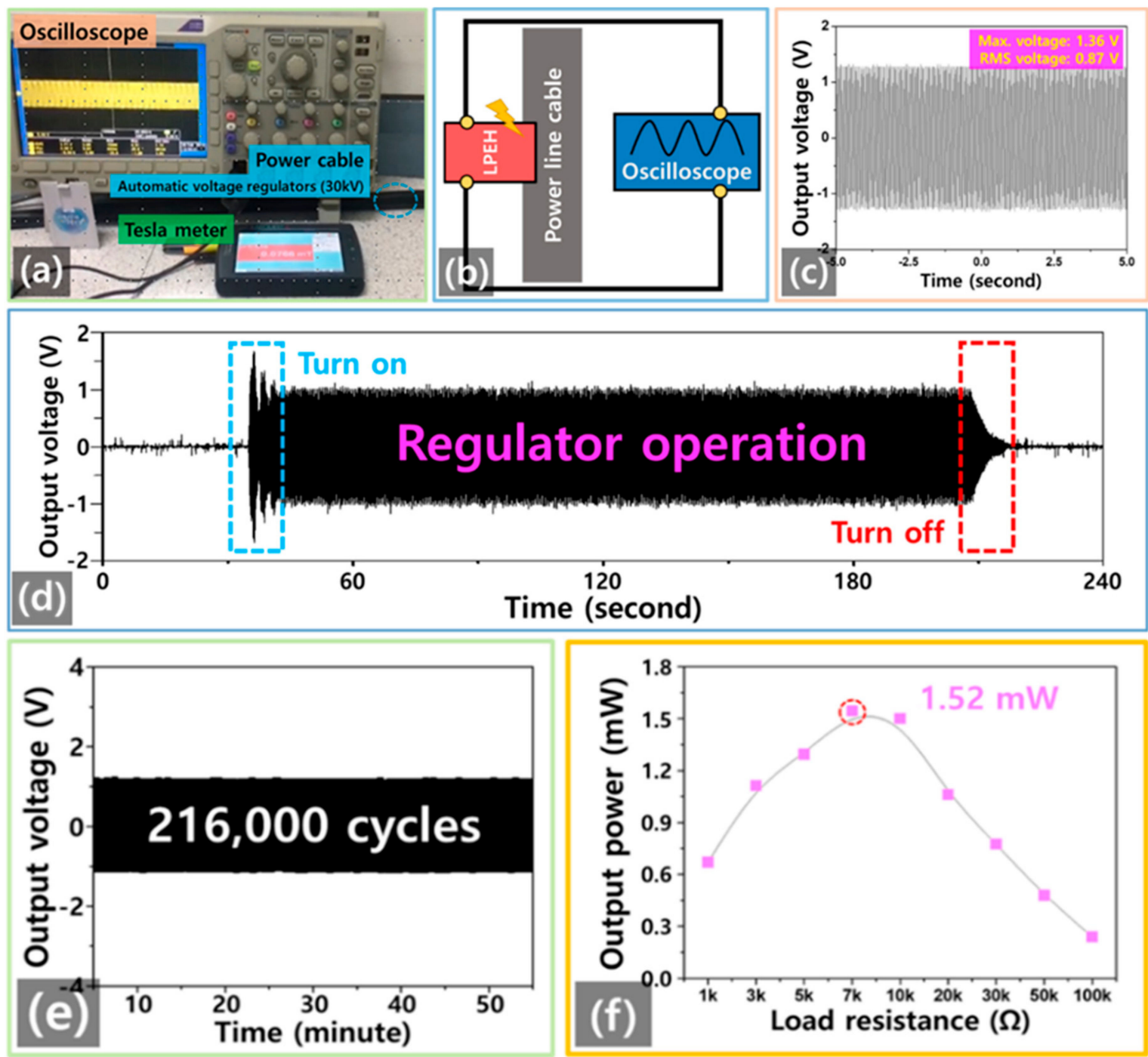

Figure 5. (a) Experimental setup to test the energy-harvesting performance from the power-line cable of an automatic voltage regulator $(30 \mathrm{kV})$. (b) Diagram of the energy-harvesting circuit with the LPEH. (c) Open-circuit voltage of the LPEH from the magnetic field of a power-line cable. (d) Open-circuit voltage of the LPEH under a regulated turn-on and -off condition. (e) Open-circuit voltage of the LPEH for a durability test over 216,000 cycles performed in a weak magnetic field of $78 \mu \mathrm{T}$. (f) Output power of the LPEH in the magnetic field of a power-line cable as a function of the load resistance (range of $1 \mathrm{k} \Omega$ to $100 \mathrm{k} \Omega$ ).

\section{Conclusions}

We developed a LPEH based on BCTZC $_{0.3}$ with a high energy-conversion constant. With the lead-free $\mathrm{BCTZC}_{0.3}$ sintered at $1450{ }^{\circ} \mathrm{C}$, we obtained both enhanced piezoelectric properties and improved energy-harvesting characteristics. The LPEH generated maximum output power that reached $8.2 \mathrm{~mW}$. Moreover, an energy density of $107.9 \mathrm{~mW} / \mathrm{cm}^{3}$ was achieved in a magnetic field of $250 \mu \mathrm{T}$, which was sufficient to drive 30 commercial LEDs. The BCTZC $_{0.3}$-based LPEH demonstrated remarkable stability without performance degradation over 126,000 cycles. The module successfully overcame earlier restrictions on power generation when using a lead-free piezoelectric energy harvester, thus enabling its operation as a self-charging energy harvester in a WSN system. The LPEH supplied electrical energy (output power: $1.52 \mathrm{~mW}$ ) constantly under a power-line cable with a weak $78 \mu \mathrm{T}$ magnetic field. The proposed approach represents a significant advance in LPEHs based on $\mathrm{BCTZC}_{0.3}$ film research for self-powering sensors in magnetic fields that could 
be used in ubiquitous wireless communication systems and also demonstrates that the technology has great commercialization potential.

Supplementary Materials: The following are available online at https://www.mdpi.com/1996-1 073/14/5/1346/s1, Figure S1: Rectifier of Self-powered wireless temperature monitoring system, Figure S2: Signal microcontroller of self-powered wireless temperature monitoring system, Figure S3: Surface FE-SEM images of the $\mathrm{BCTZC}_{0.3}$ ceramics sintered at different temperatures, Figure S4: Energy dispersive spectra (EDS) mapping analysis of the $1500{ }^{\circ} \mathrm{C} \mathrm{BCTZC}_{0.3}$ composites, Figure S5: surface images of the $\mathrm{BCTZC}_{0.3}$ sample sintered at $1500{ }^{\circ} \mathrm{C}$. Self-powered wireless temperature monitoring system and More material information can be found in the Supplementary Materials.

Author Contributions: Conceptualization, Q.W. and K.-B.K.; methodology, K.-B.K.; software, S.B.W.; validation, Q.W. and S.B.W.; formal analysis, Q.W. and K.-B.K.; investigation, Q.W. and K.-B.K.; resources, Q.W.; data curation, S.B.W.; writing—original draft preparation, Q.W.; writing—review and editing, Q.W. and T.H.S.; visualization, S.B.W.; supervision, K.-B.K. and T.H.S.; project administration, K.-B.K.; funding acquisition, K.-B.K. All authors have read and agreed to the published version of the manuscript discussions.

Funding: This work was funded by the Korea Institute of Energy Technology Evaluation and Planning (KETEP) and by the Ministry of Trade, Industry, and Energy (MOTIE) of the Republic of Korea (No. 2018201010636A). This research was supported by the Basic Science Research Program through the National Research Foundation of Korea(NRF) funded by the Ministry of Education (2019R111A1A01046810).

Institutional Review Board Statement: Not applicable.

Informed Consent Statement: Informed consent was obtained from all subjects involved in the study.

Data Availability Statement: Data is contained within the article or Supplementary Materials. The data presented in this study are available in the article or Supplementary Materials.

Acknowledgments: This work was supported by the Korea Institute of Energy Technology Evaluation and Planning (KETEP) and by the Ministry of Trade, Industry, and Energy (MOTIE) of the Republic of Korea (No. 2018201010636A). Sample images were analyzed on the FEI Scios device installed at the Hanyang LINC+ 334 Analytical Equipment Center in Seoul. This research was supported by the Basic Science Research Program through the National Research Foundation of Korea (NRF) funded by the Ministry of Education (2019R1I1A1A01046810).

Conflicts of Interest: The authors declare that they have no known competing financial interests or personal relationships that could have appeared to influence the work reported in this paper.

\section{References}

1. Siddique, A.R.M.; Mahmud, S.; Van Heyst, B. A comprehensive review on vibration based micro power generators using electromagnetic and piezoelectric transducer mechanisms. Energy Convers. Manag. 2015, 106, 728-747. [CrossRef]

2. Yildirim, T.; Ghayesh, M.H.; Li, W.; Alici, G. Design and development of a parametrically excited nonlinear energy harvester. Energy Convers. Manag. 2016, 126, 247-255. [CrossRef]

3. Lee, T.G.; Lee, H.J.; Kim, D.H.; Xu, H.; Park, S.; Park, J.S. Relation between structure and piezoelectric properties of (1-xy)PbZrO3xPbTiO3-yPb(Ni1/3Nb2/3)O3 ceramics near triple point composition. J. Eur. Ceram. Soc. 2016, 36, 4049-4057. [CrossRef]

4. Ryu, J.; Kang, J.-E.; Zhou, Y.; Choi, S.-Y.; Yoon, W.-H.; Park, D.-S.; Choi, J.-J.; Hahn, B.-D.; Ahn, C.-W.; Kim, J.-W.; et al. Ubiquitous magneto-mechano-electric generator. Energy Environ. Sci. 2015, 8, 2402-2408. [CrossRef]

5. Uzun, Y.; Kurt, E. Performance exploration of an energy harvester near the varying magnetic field of an operating induction motor. Energy Convers. Manag. 2013, 72, 156-162. [CrossRef]

6. Ryu, J; Carazo, A.V.; Uchino, K.; Kim, H.-E. Magnetoelectric Properties in Piezoelectric and Magnetostrictive Laminate Composites. Jpn. J. Appl. Phys. 2001, 40, 4948-4951. [CrossRef]

7. Zhang, J.; Wang, C.; Bowen, C. Piezoelectric effects and electromechanical theories at the nanoscale. Nanoscale 2014, 6, 13314-13327. [CrossRef]

8. Tadesse, Y.; Zhang, S.; Priya, S. Multimodal Energy Harvesting System: Piezoelectric and Electromagnetic. J. Intell. Mater. Syst. Struct. 2008, 20, 625-632. [CrossRef]

9. Saadon, S.; Sidek, O. A review of vibration-based MEMS piezoelectric energy harvesters. Energy Convers. Manag. 2011, 52, 500-504. [CrossRef]

10. Howells, C.A. Piezoelectric energy harvesting. Energy Convers. Manag. 2009, 50, 1847-1850. [CrossRef] 
11. Zhang, X.; Zhang, Z.; Pan, H.; Salman, W.; Yuan, Y.; Liu, Y. A portable high-efficiency electromagnetic energy harvesting system using supercapacitors for renewable energy applications in railroads. Energy Convers. Manag. 2016, 118, 287-294. [CrossRef]

12. Shi, Y.; Yao, H.; Gao, Y. A functionally graded composite cantilever to harvest energy from magnetic field. J. Alloys Compd. 2017, 693, 989-999. [CrossRef]

13. He, W.; Li, P.; Wen, Y.; Zhang, J.; Yang, A.; Lu, C.; Yang, J.; Wen, J.; Qiu, J.; Zhu, Y.; et al. Piezoelectric energy harvester scavenging AC magnetic field energy from electric power lines. Sens. Actuators A 2013, 193, 59-68. [CrossRef]

14. Annapureddy, V.; Palneedi, H.; Hwang, G.T.; Peddigari, M.; Jeong, D.Y.; Yoon, W.H.; Kim, K.H.; Ryu, J. Magnetic energy harvesting with magnetoelectrics: An emerging technology for self-powered autonomous systems. Sustain. Energy Fuels 2017, 1, 2039-2052. [CrossRef]

15. Fan, K.; Chang, J.; Chao, F.; Pedrycz, W. Design and development of a multipurpose piezoelectric energy harvester. Energy Convers. Manag. 2015, 96, 430-439. [CrossRef]

16. Islam, R.A.; Priya, S. Realization of high-energy density polycrystalline piezoelectric ceramics. Appl. Phys. Lett. 2006, 88, 032903. [CrossRef]

17. Priya, S.; Uchino, K.; Ryu, J.; Ahn, C.-W.; Nahm, S. Induction of combinatory characteristics by relaxor modification of $\mathrm{Pb}\left(\mathrm{Zr}_{0.5} \mathrm{Ti}_{0.5}\right) \mathrm{O}_{3}$. Appl. Phys. Lett. 2003, 83, 5020-5022. [CrossRef]

18. APC. Piezoelectric Ceramics: Principles and Applications; APC: Paris, France, 2002.

19. Seo, I.-T.; Cha, Y.-J.; Kang, I.-Y.; Choi, J.-H.; Nahm, S.; Seung, T.-H.; Paik, J.-H. High Energy Density Piezoelectric Ceramics for Energy Harvesting Devices. J. Am. Ceram. Soc. 2011, 94, 3629-3631. [CrossRef]

20. Kim, H.; Priya, S.; Stephanou, H.; Uchino, K. Consideration of Impedance Matching Techniques for Efficient Piezoelectric Energy Harvesting. IEEE Trans. Ultrason. Ferroelectr. Freq. Control. 2007, 54, 1851-1859. [CrossRef]

21. Ajitsaria, J.; Choe, S.Y.; Shen, D.; Kim, D.J. Modeling and analysis of a bimorph piezoelectric cantilever beam for voltage generation. Smart Mater. Struct. 2007, 16, 447-454. [CrossRef]

22. Lee, H.; Jang, H.; Park, J.; Jeong, S.; Park, T.; Choi, S. Design of a Piezoelectric Energy-Harvesting Shock Absorber System for a Vehicle. Integr. Ferroelectr. 2013, 141, 32-44. [CrossRef]

23. Kong, N.; Ha, D.S.; Erturk, A.; Inman, D.J. Resistive Impedance Matching Circuit for Piezoelectric Energy Harvesting. J. Intell. Mater. Syst. Struct. 2010, 21, 1293-1302. [CrossRef]

24. Brufau-Penella, J.; Puig-Vidal, M. Piezoelectric Energy Harvesting Improvement with Complex Conjugate Impedance Matching. J. Intell. Mater. Syst. Struct. 2008, 20, 597-608. [CrossRef]

25. Jaffé, B.; Roth, R.; Marzullo, S. Properties of piezoelectric ceramics in the solid-solution series lead titanate-lead zirconate-lead oxide: Tin oxide and lead titanate-lead hafnate. J. Res. Natl. Inst. Stand. Technol. 1955, 55, 239. [CrossRef]

26. Chen, H.D.; Udayakumar, K.R.; Gaskey, C.J. Electrical properties' maxima in thin films of the lead zirconate-lead titanate solid solution system. App. Phys. Lett. 1995, 67, 3411-3413. [CrossRef]

27. Liu, W.L.; Ren, X. Correlation of grain size, phase transition and piezoelectric properties in Ba0.85Ca0.15Ti0.90Zr0.10O3 ceramics. Phys. Rev. Lett. 2009, 103, 257602. [CrossRef] [PubMed]

28. Wang, P.; Li, Y.; Lu, Y. Enhanced piezoelectric properties of (Ba0.85Ca0.15)(Ti0.9Zr0.1)O3 lead-free ceramics by optimizing calcination and sintering temperature. J. Eur. Ceram. Soc. 2011, 31, 2005-2012. [CrossRef]

29. Yao, Y.; Mak, C.L. Effects of Ca-dopant on the pyroelectric, piezoelectric and dielectric properties of $\left(\mathrm{Sr}_{0.6} \mathrm{Ba}_{0.4}\right)_{4} \mathrm{Na}_{2} \mathrm{Nb}_{10} \mathrm{O}_{30}$ ceramics. J. Alloys Compd. 2012, 544, 87-93. [CrossRef]

30. Marcos, F.R.; Reinosa, J.J.; Vendrell, X.; Romero, J.; Mestres, L.; Leret, P.; Fernández, J.; Marchet, P. Structure, microstructure and electrical properties of $\mathrm{Cu} 2+$ doped $(\mathrm{K}, \mathrm{Na}, \mathrm{Li})(\mathrm{Nb}, \mathrm{Ta}, \mathrm{Sb}) \mathrm{O} 3$ piezoelectric ceramics. Ceram. Int. 2013, 39, 4139-4149. [CrossRef]

31. Hagh, N.M.; Kerman, K.; Jadidian, B.; Safari, A. Dielectric and piezoelectric properties of $\mathrm{Cu}^{2+}$-doped alkali Niobates. J. Eur. Ceram. Soc. 2009, 29, 2325-2332. [CrossRef]

32. Dhakar, L.; Liu, H.; Tay, F.E.H.; Lee, C. A new energy harvester design for high power output at low frequencies. Sens. Actuators A Phys. 2013, 199, 344-352. [CrossRef]

33. Yue, Y.; Hou, Y.; Zheng, M.; Yan, X.; Fu, J.; Zhu, M. High power density in a piezoelectric energy harvesting ceramic by optimizing the sintering temperature of nanocrystalline powders. J. Eur. Ceram. Soc. 2017, 37, 4625-4630. [CrossRef]

34. Liu, Y.; Chang, Y.; Sun, E.; Li, F.; Zhang, S.; Yang, B.; Sun, Y.; Wu, J.; Cao, W. Significantly Enhanced Energy-Harvesting Performance and Superior Fatigue-Resistant Behavior in [001]c-Textured BaTiO3-Based Lead-Free Piezoceramics. ACS Appl. Mater. Interfaces 2018, 10, 31488-31497. [CrossRef] [PubMed]

35. Kim, K.-B.; Kim, C.-I.; Jeong, Y.H.; Lee, Y.-J.; Cho, J.-H.; Paik, J.-H.; Nahm, S. Performance of unimorph cantilever generator using $\mathrm{Cr} / \mathrm{Nb}$ doped $\mathrm{Pb}(\mathrm{Zr0.54Ti0.46)O3} \mathrm{thick} \mathrm{film} \mathrm{for} \mathrm{energy} \mathrm{harvesting} \mathrm{device} \mathrm{applications.} \mathrm{J.} \mathrm{Eur.} \mathrm{Ceram.} \mathrm{Soc.} \mathrm{2013,} \mathrm{33,}$ 305-311. [CrossRef]

36. Oh, Y.; Noh, J.; Yoo, J.; Kang, J.; Hwang, L.; Hong, J. Dielectric and piezoelectric properties of CeO2-added nonstoichiometric ( $\mathrm{Na} 0.5 \mathrm{~K} 0.5) 0.97(\mathrm{Nb} 0.96 \mathrm{Sb} 0.04) \mathrm{O} 3$ ceramics for piezoelectric energy harvesting device applications. IEEE Trans. Ultrason. Ferroelectr. Freq. Control. 2011, 58, 1860-1866. [CrossRef]

37. Wu, J.; Shi, H.; Zhao, T.; Yu, Y.; Dong, S. High-Temperature BiScO3-PbTiO3Piezoelectric Vibration Energy Harvester. Adv. Funct. Mater. 2016, 26, 7186-7194. [CrossRef]

38. Seo, I.-T.; Choi, C.-H.; Song, D.; Jang, M.-S.; Kim, B.-Y.; Nahm, S.; Kim, Y.-S.; Sung, T.-H.; Song, H.-C. Piezoelectric Properties of Lead-free Piezoelectric Ceramics and Their Energy Harvester Characteristics. J. Am. Ceram. Soc. 2013, 96, 1024-1028. [CrossRef] 
39. Yan, X.; Zheng, M.; Hou, Y.; Zhu, M. Composition-driven phase boundary and its energy harvesting performance of BCZT lead-free piezoelectric ceramic. J. Eur. Ceram. Soc. 2017, 37, 2583-2589. [CrossRef]

40. Uchino, K.; Debus, J.C. Applications of ATILA FEM Software to Smart Materials: Case Studies in Designing Devices; Woodhead Publishing Limited: Cambridge, UK, 2012.

41. Uchino, K. FEM and Micromechatronics with ATILA Software; CRC Press: Boca Raton, FL, USA, 2008. 